\title{
A Counter-Rotating Impulse Turbine for Wave Energy Conversion
}

\author{
Manabu Takaoㅁ, Kohei Yamada², Shinya Okuhara3 ${ }^{3}$ M. M. Ashraful Alam¹, Yoichi Kinoue, \\ Toshiaki Setoguchi ${ }^{5}$
}

\author{
${ }^{1}$ Department of Mechanical Engineering, National Institute of Technology, Matsue College, Matsue, Japan \\ ${ }^{2}$ Advanced Course of Production and Construction Systems, National Institute of Technology, Matsue College, Matsue, Japan \\ ${ }^{3}$ Support Center for Practical Education, National Institute of Technology, Matsue College, Matsue, Japan \\ ${ }^{4}$ Department of Mechanical Engineering, Saga University, Saga, Japan \\ ${ }^{5}$ Institute of Ocean Energy, Saga University, Saga, Japan \\ Email: takao@matue-ct.jp
}

How to cite this paper: Takao, M., Yamada, K., Okuhara, S., Alam, M.M.A., Kinoue, Y. and Setoguchi, T. (2018) A Counter-Rotating Impulse Turbine for Wave Energy Conversion. Open Journal of Fluid Dynamics, 8, 435-442.

https://doi.org/10.4236/ojfd.2018.84028

Received: July 25, 2018

Accepted: December 21, 2018

Published: December 24, 2018

Copyright $\odot 2018$ by authors and Scientific Research Publishing Inc. This work is licensed under the Creative Commons Attribution International License (CC BY 4.0).

http://creativecommons.org/licenses/by/4.0/ Open Access

\begin{abstract}
Wave energy can be converted to the electrical energy by using a wave energy converter. The wave energy converter with oscillating water column (OWC) is one of the most promising devices because of its simple structure and easy maintenance. In this device, an oscillating water column due to the wave motion is used to drive an air column. An air turbine is used to convert the pneumatic energy of this bi-directional airflow into the mechanical energy. The counter-rotating impulse turbine for wave energy conversion has been proposed and tested so far, and the average efficiency has been shown to about 0.3 . On the contrary, in another offshore experiment, it has been reported that the power generation efficiency of this turbine is larger than Wells turbine in case of small waves. However, there is a scarcity of the detailed characteristics data of counter-rotating impulse turbine. In a previous study, the authors investigated the effect of rotor blade solidity and setting angle of guide vane on the performance of this turbine, and they clarified that the efficiency of this turbine is higher than impulse turbine with single rotor in the range of high flow coefficients. The present study aimed to investigate the effect of rotor blade profile on the turbine performance by using the computation fluid dynamic (CFD) analysis. The inner and outer angles of turbine rotor blade are changed in the range of $50^{\circ}$ to $70^{\circ}$. The commercial CFD software of SCRYU/Tetra of Cradle Co. Ltd. was used in the present work. The Reynolds averaged Navier-Stokes (RANS) equations were used as the governing equations and the low Reynold's number SST $k-\omega$ model was used to predict the turbulent stresses. As a result, it was found that the inner angle of $\gamma=70^{\circ}$ and the outer angle of $\gamma=60^{\circ}$ of the turbine rotor blades can give the
\end{abstract}


best turbine efficiency and it shows the efficiency close to the impulse turbine with single rotor, even in the range of low flow coefficients.

\section{Keywords}

Air Turbine, CFD, Fluid Machinery, Oscillating Water Column (OWC), Wave Energy Conversion

\section{Introduction}

The counter-rotating impulse turbine for wave energy converter with oscillating water column (OWC) was proposed by M. E. McCormick of the United States Naval Academy in 1978 [1] (Figure 1). This turbine is one of the impulse-type turbines and has two separate rotors. Thus the counter-rotors rotate uni-directionally by the air flow from either side. In 1986, a model test was performed by D. Richards et al. [2]. They reported that the average efficiency is about 0.3 . The main disadvantage of this turbine is of its complicated gearing, and its big noise generation that may be a severe problem at specific sites. Thus, it considered that the turbine is not very practical. On the contrary, another offshore experiment that was conducted at the large-scale wave energy converter "Kaimei" in 1985, reported that the power generation efficiency of this turbine is larger than the Wells turbine in the case of small waves [3]. However, there is a scarcity of the detailed characteristics data of counter-rotating impulse turbine.

The present study aims to investigate the effect of rotor blade profile on the turbine performance by using the computation fluid dynamic (CFD) analysis.

\section{CFD Analysis}

Figure 2 shows the detailed configuration of the rotor blades and guide vanes.

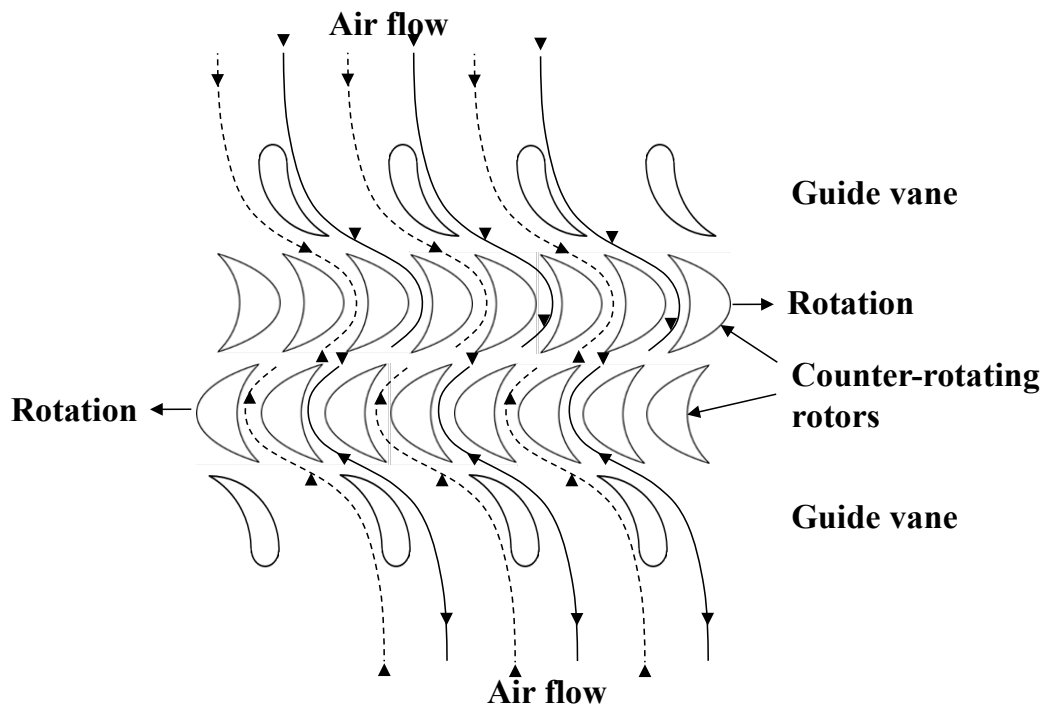

Figure 1. The details of counter-rotating impulse turbine for wave energy conversion. 


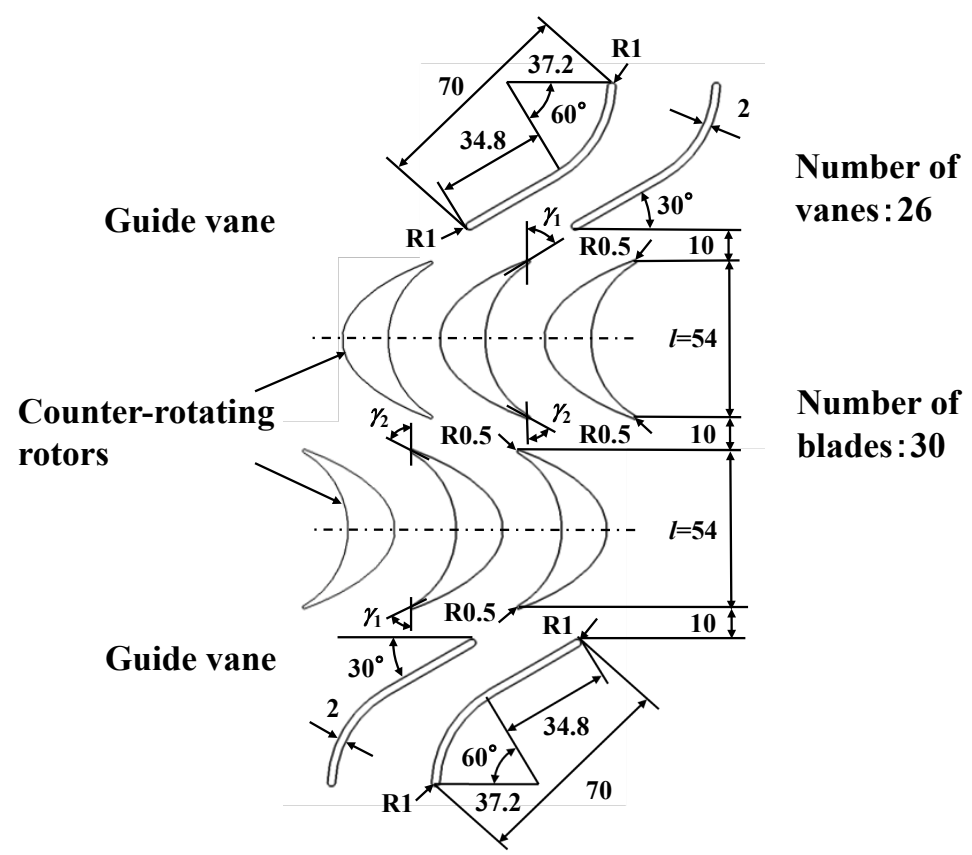

Figure 2. The configuration of rotor blades and guide vanes.

These specifications are the same as the impulse turbine with single rotor used for wave energy conversion [4].

The specification of the tested turbine rotors are as follows: casing diameter $D$ $=300 \mathrm{~mm}$; chord length $l=54 \mathrm{~mm}$; blade thickness ratio of 0.3 ; tip diameter of $299 \mathrm{~mm}$; hub diameter of $210 \mathrm{~mm}$; hub-to-tip ratio $v=0.7$; number of blades are of 30; solidity at mean radius $\sigma=2.02$.

The details of guide vanes are as follows: chord length of $70 \mathrm{~mm}$; blade thickness $t=2 \mathrm{~mm}$; number of vanes are of 26; guide vanes solidity of 2.17; setting angle of fixed guide vane is of $30^{\circ}$. In addition, although the thick-wing guide vanes were used in the McCormick's proposed turbine, it has been clarified later through conventional research that there is no difference in the performances between the thick and thin wing guide vanes [5]. Therefore, thin blades with a simple shape are used as guide vanes in this research.

In this research, the inner angle $\gamma_{1}$ and outer angle $\gamma_{2}$ of the turbine rotor blades were changed to investigate the performance characteristics of the counter-rotating impulse turbine. Figure 3 shows the changes in the configuration of the rotor conducted in this study. Type I to Type III have symmetrical rotor blade profile with inner and outer angles of $50^{\circ}$ to $70^{\circ}$, while Type IV and Type $\mathrm{V}$ have asymmetrical rotor blade profile with combination of with inner and outer angles of $60^{\circ}$ and $70^{\circ}$.

The numerical analysis was conducted using the CFD tool of SCRYU/Tetra of Cradle Co., Ltd. The computational domain used in this study consists of a casing, a cone and a counter-rotating impulse turbine, as shown in Figure 4. Considering the computational cost, half of the domain in axial symmetry was computed. The domain was composed of about 5,600,000 mesh elements. The Reynolds 


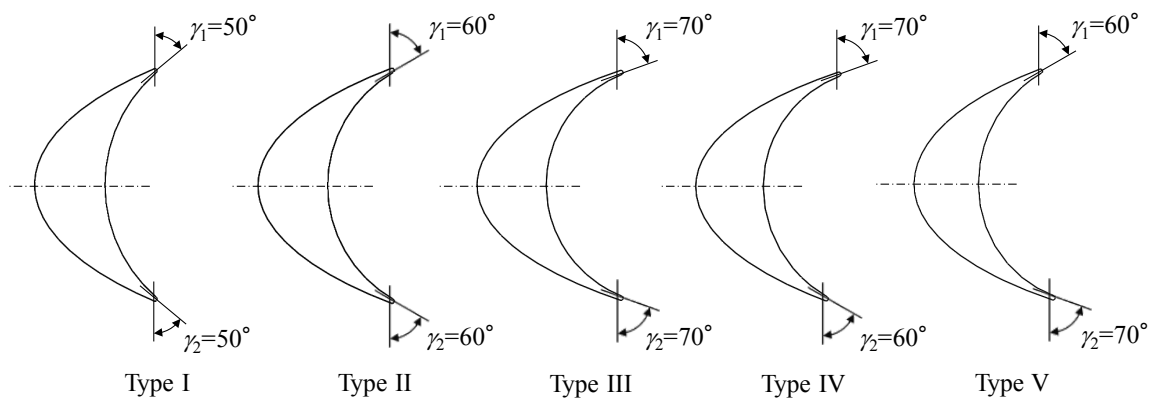

Figure 3. The configuration of rotor blades.

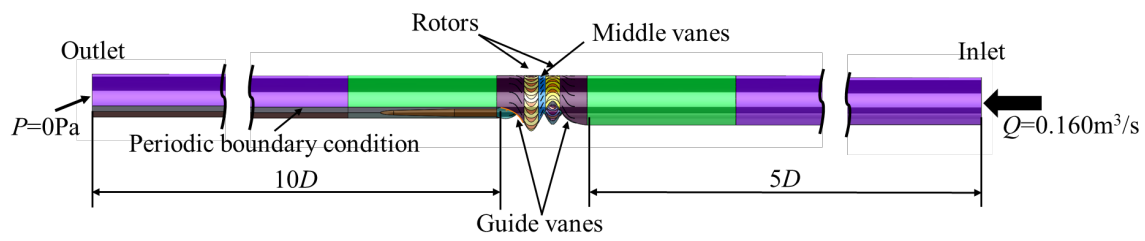

Figure 4. Computational domain and boundary condition.

averaged Navier-Stokes (RANS) equations were used as the governing equations, and to predict the turbulent stresses the low Reynold's number SST $k-\omega$ model was used. The flow was considered as steady-state, and the non-slip boundary condition was set to the solid boundaries. The flow rate at the inlet was kept constant at $Q=0.32 \mathrm{~m}^{3} / \mathrm{s}$. The outlet was opened to the atmosphere. Turbine rotation was modeled by the steady Arbitrary Lagrange-Eulerian (ALE) method.

\section{Performance Evaluation}

The turbine performance under steady flow conditions was evaluated by the torque coefficient $C_{T}$, input coefficient $C_{A}$, flow coefficient $\phi$ and efficiency $\eta$. The definitions of these parameters are as follows:

$$
\begin{gathered}
C_{T}=T_{o} /\left\{\rho\left(v^{2}+u^{2}\right) A r / 2\right\} \\
C_{A}=\Delta p Q /\left\{\rho\left(v^{2}+u^{2}\right) A v / 2\right\}=\Delta p /\left\{\rho\left(v^{2}+u^{2}\right) / 2\right\} \\
\eta=T_{o} w /(\Delta p Q)=C_{T} /\left(C_{A} \phi\right) \\
\phi=v / u
\end{gathered}
$$

where $A, r, u, v$ and $\rho$ denote the flow passage area $\left\{=\pi D^{2}\left(1-v^{2}\right) / 4\right\}$, mean radius $\left\{=\pi D^{2}\left(1+v^{2}\right) / 4\right\}$, circumferential velocity at mean radius $(=R \omega)$, axial flow velocity $(=Q / A)$ and density of air, respectively.

\section{Results and Discussion}

Since the experimental data of counter-rotating impulse turbine has not yet been published, the experimental data of impulse turbine with single rotor for wave energy conversion was used to validate the CFD works [6].

Figure 5 shows the comparison between the experimental and numerical results of the impulse turbine with single rotor. The turbine performance was examined 


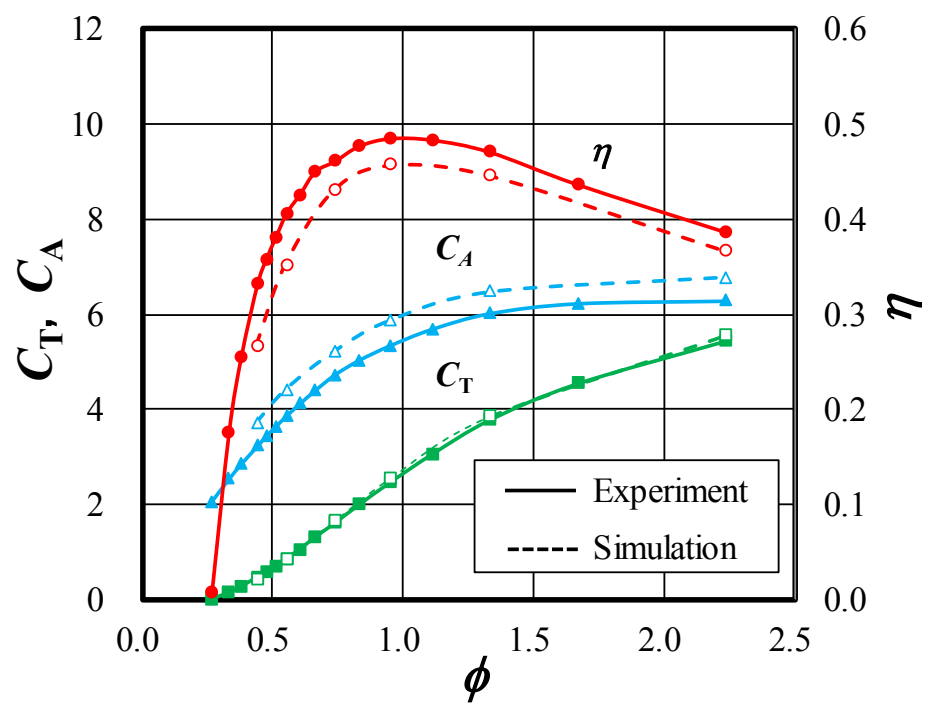

Figure 5. The flow characteristics of impulse turbine with single rotor.

under the steady flow by a wind tunnel test. Although the numerically obtained results is bit under predicted, the predicted turbine characteristics show a good qualitative agreement with the experimental data.

Figure 6 shows the predicted results of the effect of symmetrical rotor blade profiles on the performance characteristics of counter-rotating turbine. From figure, the torque coefficient $C_{T}$ increases with the inner angle $\gamma_{1}$ and outer angle $\gamma_{2}$. On the other hand, input coefficient $C_{A}$ increases with $\gamma_{1}$ and $\gamma_{2}$. From these characteristics data, the turbine with Type III profile of rotor blade shows the highest efficiency. A comparison between the impulse turbine with single rotor and counter-rotating impulse turbine of Type III profile shows that the counter-rotating impulse turbine has a higher $C_{T}$ than the impulse turbine. However, the difference in $C_{A}$ is much larger at same flow rate of two rotors. From these results the counter-rotating impulse turbine shows a better efficiency than the impulse turbine in the range of high flow coefficient, and it shows the efficiency close to the impulse turbine, even in the range of low flow coefficients.

Figure 7 shows the predicted results of the effect of asymmetrical rotor blade profile on the performance characteristics of counter-rotating turbine. The results of Type III turbine profile are also presented in these figures for comparison. The torque coefficient $C_{T}$ is higher in the order of Type III, Type V, Type IV. On the other hand, the input coefficient $C_{A}$ in Type III profile is the highest. From these characteristics data, in case of Type III and Type V rotor blade profiles, the turbines show the highest efficiencies. Furthermore, in the consideration of primary conversion efficiency at the air chamber of oscillating water column (OWC), the Type $\mathrm{V}$ profile is considered to be a suitable rotor blade profile of the counter-rotating impulse turbine because its $C_{A}$ is smaller than Type III profile.

Figure 8 shows the velocity triangles at peak efficiency $(\phi=1.33)$. Here, $u, v$, $w, \alpha$ and $\beta$ donate the circumferential velocity of rotor, absolute velocity, relative 


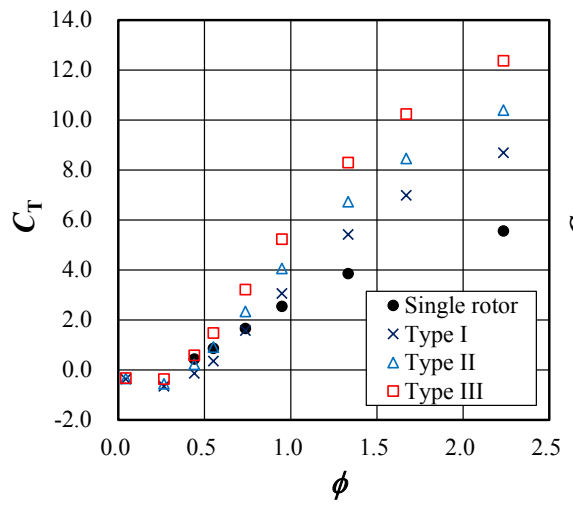

(a)

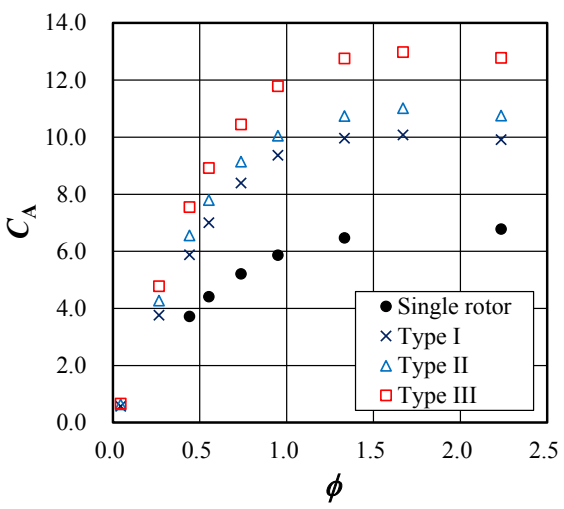

(b)

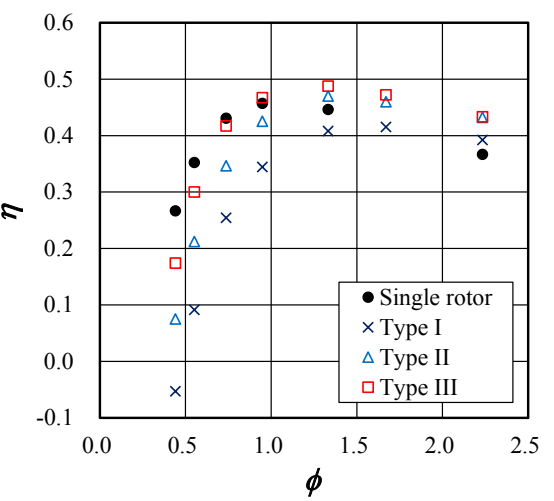

(c)

Figure 6. Effect of symmetrical rotor blade profile on turbine characteristics. (a) Torque coefficient; (b) Input coefficient; (c) Efficiency.

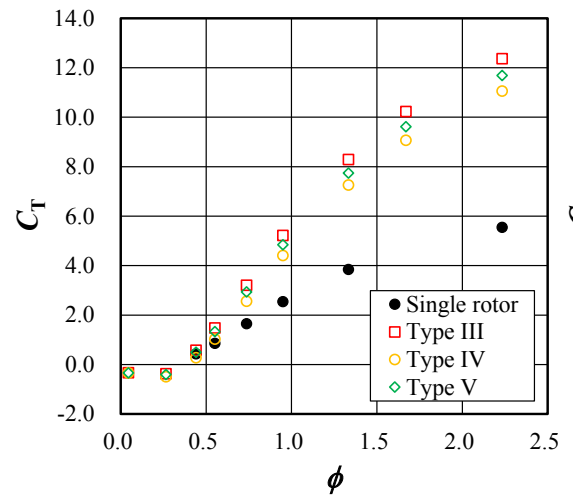

(a)

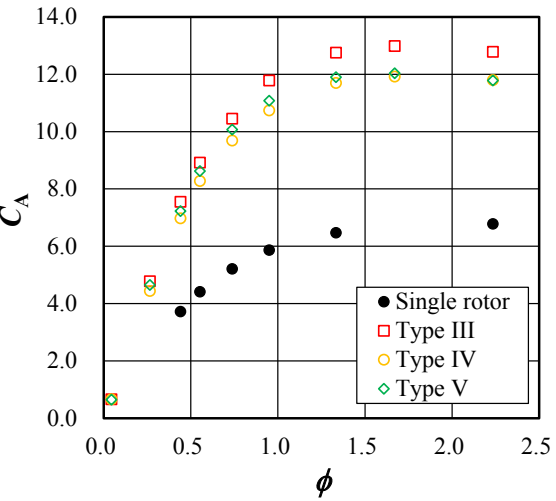

(b)

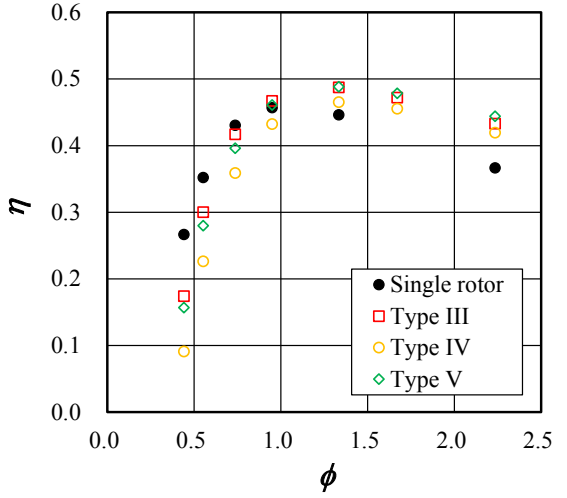

(c)

Figure 7. Effect of asymmetrical rotor blade profile on turbine characteristics. (a) Torque coefficient; (b) Input coefficient; (c) Efficiency.

velocity, inflow relative angle of rotor, and outflow absolute angle of rotor, respectively. Subscripts 1 to 4 indicate the inlet and outlet of each rotor. From figures, it can be seen that the swirling component of the absolute velocity at each rotor increases as the inner angle $\gamma_{1}$ and outer angle $\gamma_{2}$ of the turbine rotor blades increases. Therefore, Type III profile is obtained the greatest torque because it can produce the most swirl component of the absolute velocity at each rotor.

Figure 9 shows the pressure distributions at peak efficiency $(\phi=1.33)$. From figures, the pressure difference across the turbine is higher in the order of Type III, Type V, Type I because Type III has larger shock loss and friction loss at flow path than Type $\mathrm{V}$ and Type I profiles.

\section{Conclusions}

The performance analysis of counter-rotating impulse turbine for wave energy conversion was investigated numerically by using CFD analysis in the study. The obtained results are summarized as follows:

1) The counter-rotating impulse turbine with Type III rotor profile shows 


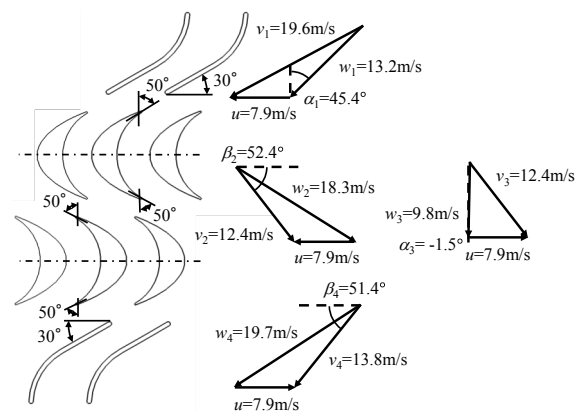

(a)

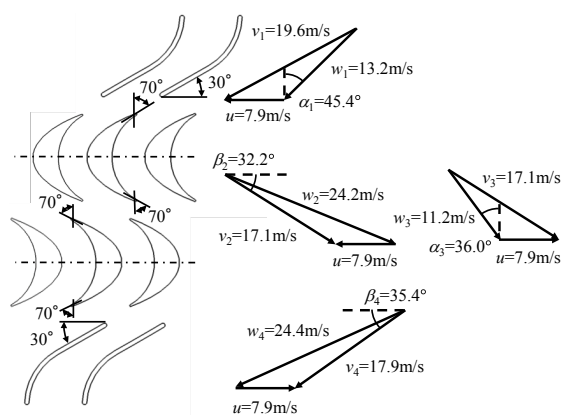

(b)

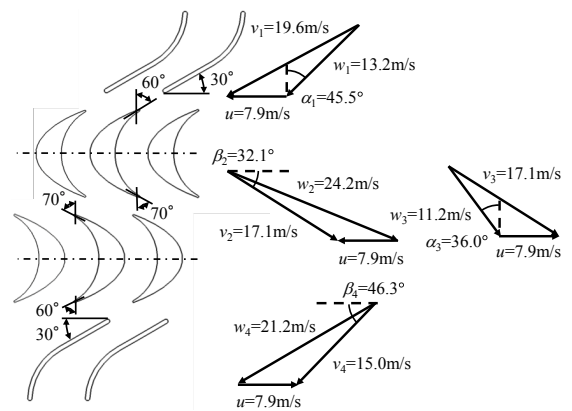

(c)

Figure 8. Velocity triangles ( $\phi=1.33$ ). (a) Type I; (b) Type III; (c) Type V.

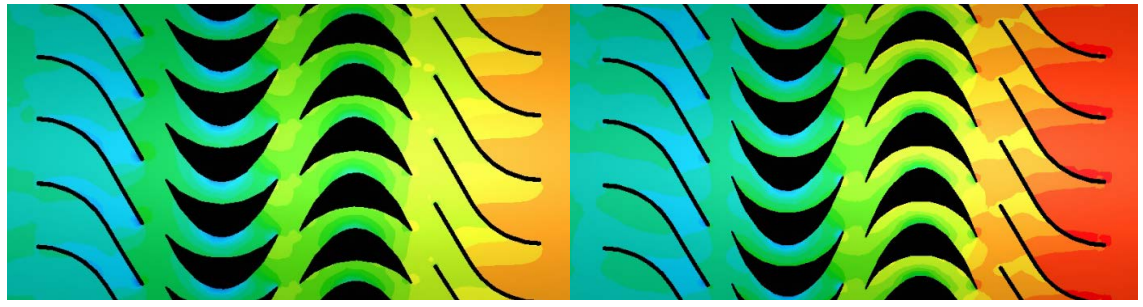

(a)

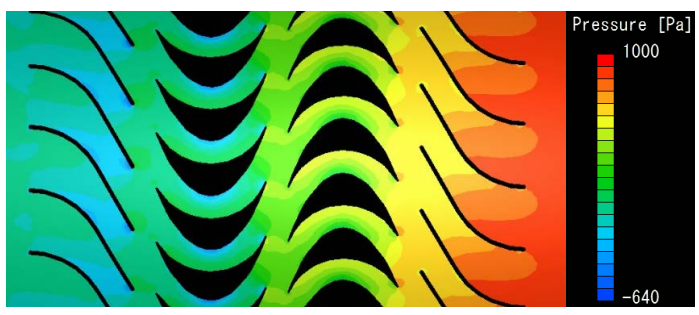

(c)

Figure 9. Pressure distributions ( $\phi=1.33$ ). (a) Type I; (b) Type III; (c) Type V.

higher efficiency in a wider range of flow coefficients than the impulse turbine with single rotor.

2) In the consideration of primary conversion efficiency of oscillating water column (OWC), Type V profile is considered to be a suitable rotor blade profile of the counter-rotating impulse turbine.

\section{Conflicts of Interest}

The authors declare no conflicts of interest regarding the publication of this paper. 


\section{References}

[1] McCormick, M.E. (1981) Ocean Wave Energy Conversion. Wiley-Interscience, New York.

[2] Richards, D. and Weiskoph Jr., F.B. (1986) Studies with, and Testing of the McCormick Pneumatic Wave Energy Turbine with Some Comments on PWECS Systems. Proc. of Int. Symp. on Utilization of Ocean Waves-Wave to Energy Conversion, La Jolla, California, 16-17 June 1986, 80-102.

[3] Masuda, Y. (1987) Wave Energy Conversion in Japan, Kasumi, Tokyo. (In Japanese)

[4] Setoguchi, T., Takao, M., Kinoue, Y., Kaneko, K., Santhakumar, S. and Inoue, M. (2000) Study on an Impulse Turbine for Wave Energy Conversion. International Journal of Offshore and Polar Engineering, 10, 145-152.

[5] Setoguchi, T., Santhakumar, S., Maeda, H., Takao, M. and Kaneko, K. (2001) A Review of Impulse Turbine for Wave Energy Conversion. Renewable Energy, 23, 261-292. https://doi.org/10.1016/S0960-1481(00)00175-0

[6] Okuhara, S., Takao, M., Takami, A. and Setoguchi, T. (2013) Wells Turbine for Wave Energy Conversion-Improvement of the Performance by Means of Impulse Turbine for Bi-Directional Flow. Open Journal of Fluid Dynamics, 3, 36-41. https://doi.org/10.4236/ojfd.2013.32A006 